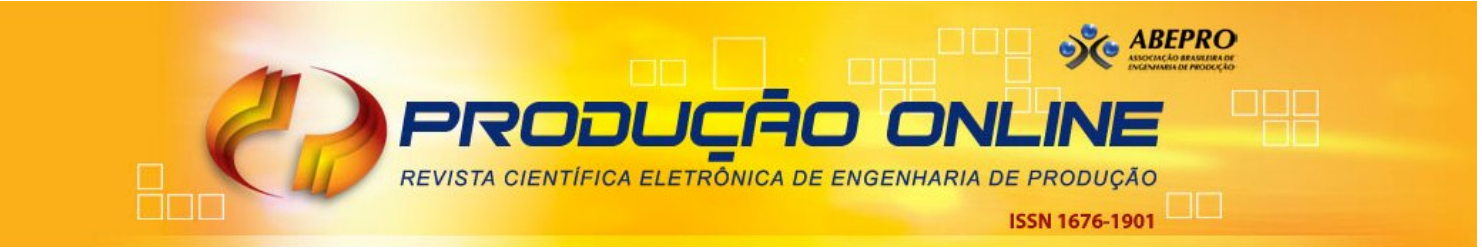

\title{
INTEGRATION OF EVIDENCE-BASED AND EXPERIENCE-BASED DESIGN: CONTRIBUTIONS FROM A STUDY IN A HEALTH CARE SERVICE
}

\section{INTEGRAÇÃO DO DESIGN BASEADO EM EVIDÊNCIAS E EXPERIÊNCIAS: CONTRIBUIÇÕES DE UM ESTUDO EM SERVIÇO DA SAÚDE}

\author{
Mirela S. da Rosa * E-mail: mirela@noladesign.com.br \\ Gustavo S. de Borba* E-mail: gborba@unisinos.br \\ Rodrigo P. Leis * E-mail: rodrigo@produttare.com.br \\ Guilherme L. R. Vaccaro* E-mail: guilhermev@unisinos.br \\ *University of Vale do Rio dos Sinos (UNISINOS), São Leopoldo, RS
}

\begin{abstract}
The purpose this paper is to present an integrated study of Service Design and the Mechanism of the Production Function (MPF) for redesigning the health care services to improve the perceived value of the patient and increase the productivity of hospital operations by eliminating wastes. The method used was action research and applied in an ICU of a private hospital in southern Brazil. The techniques of participant observation, interviews, archival research and meetings co-creation with a team of the hospital were used to collect data. Data were analyzed through content analysis of the interviews and the Design Service and Production Engineering tools. Evidence based approaches tends to contribute to the replication of the project outcomes in future cases. The MPF can support project development in the field of Design, as well the integrated approach developed in the healthcare sector, helped to devote more time to the phases of diagnosis and implementation. The findings are useful to demonstrate that can use simultaneously approaches the Service Design and MPF for the development of more robust solutions in health care environment. Further research could be done in other private or public hospitals as well as in other hospital units besides the ICUs. Limitations include the work done in a single hospital and service unit, data collected from a small group of people in the hospital. Integrating Evidence-Based Design, Experience-Based Design and the MPF can produce a more robust way to justify and define the focus of improvements in health care services.
\end{abstract}

Keywords: Service Design. Health care. Intensive Care Unit. Mechanism of the Production Function. Hospital.

Resumo: O objetivo desse artigo é apresentar um estudo que integra o Design de Serviço e o Mecanismo da Função Produção (MFP) para redesenhar os serviços de cuidado da saúde a fim de melhorar a percepção de valor do paciente e o aumento da produtividade das operações de um hospital através da eliminação de suas perdas. O método de pesquisa utilizado foi o da pesquisação tendo sido aplicado em um Centro de Tratamento Intensivo (CTI) de um hospital privado do Sul do Brasil. As técnicas de observação participante, entrevistas, pesquisa em arquivo e reuniões de co-criação com uma equipe do hospital foram utilizadas na coleta de dados. Os dados foram analisados através de análise de conteúdo a partir das entrevistas e de ferramentas do Design de Serviço e da Engenharia de Produção. A abordagem baseada em evidências tende a contribuir para que os resultados do projeto possam ser replicados em casos futuros. O MFP pode apoiar o desenvolvimento de projetos na área do Design, assim como a abordagem integrada desenvolvida na área hospitalar, apontando para a dedicação de mais tempo nas fases de diagnóstico e implantação. Os resultados são úteis para 
demonstrar que as abordagens do Design de Serviço e do MFP podem ser utilizadas simultaneamente para o desenvolvimento de solução mais robustas no ambiente hospitalar. Pesquisas futuras podem ser feitas em outros hospitais privados ou em hospitais públicos, assim como em outras unidades de um hospital que não sejam em CTIs. As limitações da pesquisa incluem o fato de que o trabalho feito ocorreu em apenas um hospital e em uma única unidade de serviço, além dos dados terem sido coletados a partir de um pequeno grupo de profissionais do hospital. A integração do Design baseado em Evidências, do Design baseado em Experiências e do MFP podem produzir formas mais robustas para justificar e definir o foco das melhorias em serviços hospitalares.

Palavras-chave: Design de Serviço. Cuidados da Saúde. Centro de Tratamento Intensivo. Mecanismo da Função Produção. Hospital.

\section{INTRODUCTION}

In several countries, Economy is moving from material basis (manufacture) to immaterial basis (services). As technological development increases, access to both supplies and information, as well as to convergent technologies, lead to a servitization of goods. Trends involve the concepts of product-service-systems and mass customization, among others. This context of service infusion in Economy correlates to an increasing on the rigor about what users consume. As Lockwood and Walton (2008) state, in this context, consumers' requirements demand a stronger differentiation effort. And companies see the offer of services as an opportunity for enabling emotional bonding with their brands through customization. As a consequence, areas focused on designing creative solutions for brands and products start to focus their attention on the development of methodologies able to delineate the offering of services aligned to the value or experience desired by the end consumer, enabling new ways of service development (FREIRE and SANGIORGI, 2010).

In a particular perspective of services, Healthcare can benefit from such new ways of value focused service design. Along time, Hospitals have been trying to deliver more efficient, effective and valuable services. In this context, value is not restricted to profit, but to the intent of maximizing the benefit/cost relation. For this, there is a continuous emphasis on studies about how these services can be modified or improved (GRAZIER, 1999; ARREGUY-SENA et al., 2001; SILVA et al., 2006).

According to Rottingen et al. (2009), applying Design on Healthcare must consider a sum of elements of experience, like performance, engineering, and aesthetics. In such view, the medical emphasis on evaluations and evidences should inspire service designers not only to create processes, but also to demonstrate the 
impact by them generated, through data and evidences, to inform decisions (past evaluations), and to improve the practice (future evaluations).

Bate and Robert (2006) investigates possible ways of using Design for reforming the Healthcare system, aiming at a large-scale change. Their study is based on applied case analyses looking to the different perspectives a Service Design (SD) project can take, aiming to propose more effective solutions for this sector. EvidenceBased Design (EBD) and Experience-Based Design (ExBD) are highlights in such context. EBD is a research line that tries to "revolutionize the way how design is applied" and increase its quality level (BRANT et al., 2010). ExBD, on the other hand, has, as main goal, turning the service or the product experience unique and better for the user, starting from his or her involvement in the Design process (BATE and ROBERT, 2006).

Both EBD and ExBD approaches present remarkable benefits, as they also present limitations for their isolated appliance on the healthcare context. Aggregating both approaches seem to present a relevant path (CARR et al., 2011) of development and research. The incorporation of Operations Management (OM) and Industrial Engineering (IE) techniques to SD in Healthcare Systems, such as the Mechanism of Production Function (MPF), Lean approaches, Simulation and Optimization, among others (BORBA, 2005), can also lead to more valuable, effective, EBD and ExBD approaches.

This paper discusses the advantages of using an integrated approach SD+MPF in the healthcare sector. The discussion is based on an action research developed in an Intensive Care Unit (ICU) of a Brazilian reference hospital. The study was focused on the operations performed by the nursing technicians', once these professionals interact more frequently with patients and their relatives/visitors, as well as perform the major part of the tasks in ICU flow. These subjects create positive or negative bonds with the patients and their relatives, and frequently notice a problem before any other member of the team.

Literature search on the EBSCO database reveals an apparent lack of academic work, whether theoretic or empiric, integrating SD, OM/IE and healthcare. From the featured index, considering peer-reviewed publications from 2002 to 2012, only three works (WYE, SHAW and SHARP, 2008; VAN STAA et al., 2009; CARR et al., 2011) congregate such themes in the same sense intended in this research. The work of Carr 
et al. (2011), which examines the potential integration of EBD and ExBD approaches to develop creative solutions for the services of a healthcare organization in England, it the one that best aligns to the goals of this paper. In their study, the authors describe that the EBD approach supports interpreting protocols and guidelines with a quantitative emphasis, while ExBD allows considering specific requirements of both the patient and the context.

The use of the patient's point of view as a key-concept in SD adds value to the contemporary efforts for improving healthcare processes, considered the benefits of integrating quanti-qualitative methods. In such sense, Bate and Robert (2006) defend the research of different approaches for SD development, as an evolution of the way in which changes happen. This includes the evolution to more patient-centered services in Healthcare.

\section{BACKGROUND}

\subsection{Service Design on Healthcare Systems}

According to Bate and Robert (2006), the areas of Healthcare and Design share the common goal of making something better for their users: a "good design" of a healthcare service is not necessarily different from a good project in any other area. And it must contemplate three aspects: (i) performance - how much the product or service fulfills its function, which, regarding the healthcare context, means how efficiently the work of treating and taking care of the patients is done; (ii) engineering - how safe and well designed is the product's engineering, or, regarding services, its delivery (without damages or errors, with consistence, durability and confidence); and (iii) aesthetics - how good is the experience, how the user sees it and feels well while interacting with the service or using the product.

The association between improving healthcare's processes and services and improving patients' experience present a relevant topic of research with practical application. According to Ericson (2009), every healthcare experience is formed by a collection of interaction systems. The Center for Healthcare Design has analyzed more than 600 researches and has demonstrated a straight connection between the patient's health, the care service's quality, and the healthcare design (LEE, 2011; 
ZIMRING, 2004). Much has had been written about the operational, technological, diagnosis and health treatment structures. Nevertheless, the emotional systems end up being less explored. Next to the tangible elements are the expectations, the perceptions, the motivations, the behaviors and the decisions. Thus, three key-actors have to be considered in a so-called healthcare emotional system: the patient, the doctor, and the patient's companion (relative or friend). The patient occupies the central position in this network, thus effective experiences must be projected to provide the appropriate information, to give a sense of control, and to create an atmosphere of care and confidence for these actors (ERICSON, 2009).

In the same context, Zimring (2004) stresses that finding methods to improve patients' answers, their safety and satisfaction, as well as workers' retention and service's efficiency is key for a well-designed healthcare service. Bate and Robert (2006) confront this view, stating that focusing solely on the user and ignoring necessities and interests of the internal workers is giving a step back, because the emphasis must be on co-design, in involving providers and receptors of the service. Lovlie et al. (2009) also state that, despite information and knowledge are central elements in healthcare, a user-led approach has limitations, opening space for data and indicators to inform decisions (past evaluations) and to improve the practice (future evaluations).

As in a knowledge intensive field, the quality of the healthcare services provided depends directly of the effectiveness and commitment of each employee who has contact with the patient. Training, knowledge sharing, collaborative work and collective willpower converge to create cultural change. Large scale changes in healthcare organizations do not necessarily depend on external conductors, but on the ability of connecting and mobilizing people, creating a bottom-up movement for development and change (BATE et al., 2004). In such sense, Bate and Robert (2006) defend intensifying the search for "better" and more efficient theories and approaches for large-scale changes and for the transformation of the systems as a whole, especially those with participatory purposes.

Among the possible existing theoretical approaches to treat SD in healthcare systems, ExBD and EBD present as alternatives (CARR et al., 2011), as presented in the next section. 


\subsection{Evidence-Based Design and Experience-Based Design}

Evidence-Based Design (EBD) emerged as an approach to improve Design's quality and capacities. EBD focuses on creating more useful and sustainable products and services and making designers search for scientific methods as a way to improve the project's results. At first, the evidence-based concept implies that project's demands can come up from scientific evidence, obtained most of the times by academic research, risk-benefit analysis or meta-analysis of a series of studies. Generally, the goal is the improvement on either quality or risk management of a service, product or process (CARR et al., 2011).

In the same sense, Brandt et al. (2010) point out that design professionals depend typically on intuition and personal experience to make choices during the project process. Decision making, thus, works on a certain level, but is limited to selfknowledge and self-experience. EBD proposes the use of investigation, computer simulations and other techniques to predict possibilities and reduce costs, as well as to collect data during creation, to convince the stakeholders about investment and test the prototypes quantitatively. Evidences are necessary to understand how specific Design strategies can affect products', constructions' or services' performances, in order to develop forecasts.

According to Zimring (2004), EBD in healthcare services can: (i) increase the patient's safety, reducing risks of infection, wounds due to falls, and clinical errors; (ii) eliminate environmental stress factors, like noises, that negatively affect patient's responses and workers' performance; and (iii) reduce stress and promote cure, making hospitals more pleasant, comfortable and welcoming for patients and workers. Carr et al. (2011) analyze that, in practical terms, EBD is frequently used on a large-scale projects as to build hospitals, as part of management and evaluation, and tries to standardize the procedures to guarantee predictable patients' responses.

On the other hand, Experience-Based Design (ExBD) consists of two main elements: (i) the participative involvement of users in the Design process; and (ii) the experience, focusing on the improvement of service or product experience as a whole, concerning how the client perceives it. ExBD focus on improving the product or the service through the user's eyes. The nature of the change is based on understanding the experience in a profound level, always keeping in mind that it involves the 
subjective physical, sensorial, cognitive, emotional and aesthetic aspects, and knowing how to use these can create more successful and complete services than before. Customers have a type of knowledge that other involved actors have no access to, once they are the first to experience the product or service intending to effectively use it, so they have special insights that can help making the service better in the future (BATE and ROBERT, 2006).

Carr et al. (2011) alert that radical tools are necessary to perform the transforming change on services and there are no evidences that small-scale studies referred as ExBD have the power to influence or boost radical transformations. The comprehension of the factors that contribute for a more complete user experience at a large organization is a complex process that involves management systems and processes that many practitioners of ExBD do not consider.

Due to the benefits and weaknesses of basing design only on the user's experiences or on the evidences of the service, integrating these two approaches seems to be a way for improving the SD methodology. The effectiveness of the EBD approach lies on the provision of protocols and processes for the success of interventions of the project, but it lacks of overall effective engagement of stakeholders interested in interpreting and translating the guidelines on the local context. On the other hand, the tools and methods developed by the ExBD approach can provide a counterpoint to these prescriptive approaches, increasing the specificity of the standard through a profound comprehension of the local user's experience, favoring the participation of all the interested ones in reflecting about the current experiences with the service, imagining alternatives and being part of the process's redesign (CARR et al., 2011). This bottom-up approach has proven to be more effective in promoting behavior changes in the individuals and, when combined with the EBD systems approach, offers an integrated perspective that can provide the ideal environment to conceive and, effectively, implement proposes of redesign services in the health environments.

Due to the complexity of fields such as Healthcare, this integrated approach seems to be particularly interesting (CARR et al., 2011). Following this integrated view, standards and process' systems, concepts that have been dominating the field of healthcare services for almost a decade, would need to stay next to aesthetics and subjective matters, considered simultaneously, never as isolated elements (BATE and 
ROBERT, 2006). The central point of this approach in the current context is that hospitals should not only turn the real treatment safer, but also make the patients feel safer. In this approach, still there is a great necessity of process mapping, care service programs development, and other traditional and well-established methods and tools (BATE and ROBERT, 2006).

\subsection{The Mechanism of the Production Function}

The concepts of 'operation' and 'process' are central to the field of OM/IE, regarding performance, structure and efficiency of production or service systems. Shingo (1996) argues that all productive systems can be understood as a functional network of operations and processes: (i) the processes follow the material, customer, information in time and space; and (ii) the operations follow the flow of the work subjects (machines and workers) in time and space (ANTUNES et al., 2008). This network is called the Mechanism of the Production Function (MPF).

This concept allowed Toyota to create a series of concrete actions for improving its productive system performance, supported by the other concepts such as productive losses, standardization, pull-production and autonomation, among others (OHNO, 1997; SHINGO, 1996). The orientation for processes, as a means for getting better results, is other fundamental element to understand Toyota's culture: the right processes will lead to the right results (ANTUNES et al., 2008). The main goal of improvement projects is thus eliminating wastes during the processes (LIKER, 2005).

For performing significant improvement on the production process, it is necessary to distinguish the production flow (process) from the subject flow (operation), and analyze them separately. MPF's allows identifying seven wastes connected to the process and operation functions. Five wastes are related to the process function: overproduction, stock, waits, processing, and transportation. Two other wastes are mostly related to the operation function: internal movements, and fabrication of defective products (SHINGO, 1996). Elimination of these wastes must be a priority, in order to systematically reduce costs and improve productiveness. Improvements made on operations without considering their impacts on processes can, in fact, produce a local operational efficiency, but not a global operational efficiency (Shingo, 1996) and a better relation between profit and investment. 
By analyzing the healthcare environment from the perspective of MPF, it is possible to apply the concepts here briefly presented to identify sources of wastes in healthcare processes (Table I), as well as analyzing the impacts of actions focused on improving such processes (SILVA et al., 2006).

Table I - Interpretation of wastes in healthcare environments

\begin{tabular}{|c|c|}
\hline Waste & Examples for interpretation in healthcare environments \\
\hline Overproduction & $\begin{array}{l}\text { During the service deliverance } \\
\text { Ex: Excessive or unnecessary examinations }\end{array}$ \\
\hline Stock & $\begin{array}{l}\text { Stock control and patient management } \\
\text { Ex: Medicine degradation, infection of patients during recovery }\end{array}$ \\
\hline Wait & $\begin{array}{l}\text { During the service deliverance } \\
\text { Ex: Queues during service delivery }\end{array}$ \\
\hline Transportation & $\begin{array}{l}\text { During the service deliverance } \\
\text { Ex: Risk associated to the transportation of patients among different parts } \\
\text { of the healthcare system }\end{array}$ \\
\hline Processing & $\begin{array}{l}\text { Unnecessary or redundant operations for solving the same problems } \\
\text { Ex: Registration of information which is never used for subsequent } \\
\text { processes }\end{array}$ \\
\hline Movement & $\begin{array}{l}\text { From operators and technicians } \\
\text { Ex: unnecessary movements from physicians, operators and technicians }\end{array}$ \\
\hline Defective items & $\begin{array}{l}\text { Inadequate service delivery or protocol deviance } \\
\text { Ex: Errors during treatment, inadequate registration of information }\end{array}$ \\
\hline
\end{tabular}

Source: adapted from Shingo (1996)

\section{METHODOLOGY}

This study follows an exploratory orientation, based on the Action Research strategy. Thus researchers and key participants are involved in a cooperative and participative manner, having an active role in collecting data and solving a collective problem (THIOLLENT, 1997). The Action Research approach enables both SD and MPF analysis, marked by the openness and the participation of researchers and insiders, providing knowledge that can be processed into information through the analytic background of EBD and ExBD in the context of the particular healthcare organization. This strategy implies that results cannot be generalized, even they can 
lead to particular decision making as well as they can serve as contribution for a base of cases from where emergent patterns can raise.

The research was developed at Hospital Mãe de Deus (HMD), in Porto Alegre, Brazil. Founded in 1979, HMD strives for quality and quantity of services and assistance services available for the community. The hospital comprehends a built area of approximately 40 thousand square meters, with a medical team of more than 4 thousand accredited physicians. The medical services available are: Emergency, Day Hospital (prepared for outpatient procedures), Intensive Care Unit (ICU), Dialysis Center, Maternity, Neonatal ICU, Obstetric Center, Surgery Bloc, Blood Bank and more than 370 hospital beds. Furthermore, it has a medical structure of institutes, which are specialized spaces that centralize complete and differentiated services, with multidisciplinary treatment (HMD, 2012).

The analysis unit was the Intensive Care Unit (ICU) of HMD, focused on caring severe or risk-condition adult patients who need nonstop medical and nursing assistance. ICU provides proper specific equipment and specialized human resources, enabling access to other diagnosis and therapy technologies (ROVATTI, 2010). The profile of the patients under the care of the ICU team comprehend different diagnosis (from clinical to surgical), consuming, at least on the first hours of hospitalization, all the kinds of available resources, such as mechanical ventilation, heart monitors, infusion pumps, 24/7 nursing, pharmacology and specific exams.

Data was collected from Nov/2011 to Nov/2012 through participant observation, interviews, documental research, and co-creation meetings with the members of the project. The study was performed in four stages, as will be presented in the following section. All people involved were invited for voluntary participation based on a strict protocol previously established with the ICU managers and following the orientations of HMD's Ethics and Research Committee.

Participant observation was used for understanding daily routines of nursing technicians and other actors of the ICU. Special attention was given for local cultural elements, the relation with other actors and with the physical evidences, and to failures and improvement opportunities (ANGROSINO, 2009). SD tools like stakeholders map, shadowing and workday map, and OM/IE concepts such as MPF and production wastes supported this stage of the research. For starting, the researchers conducted a two-hour workshop explaining the goals, the expected results and the research 
methodology to the teams of the three work-shifts of the ICU. This process took five months, during the diagnosis stage.

The research team conducted 12 interviews with assistant doctors, routine doctors, nursing technicians, psychologists and patients' companions. The goal was to comprehend the motivations, the values and the expectations (ANGROSINO, 2009) of these actors regarding the ICU services. The same script of interview was used in all cases, and the results were summarized using SD tools - stakeholders map, client's workday map and expectations map.

The co-creation meetings were conducted with the ICU employees and managers, aiming at examining observed elements based on their specialized knowledge, and collecting information about their individual perceptions about the ICU's service delivery. This technique consists in developing meetings with the relevant actors for the analysis, for them to show their ideas and opinions regarding a researched service or process (VAN DIJK et al., 2010). Workday maps, and creation and service prototypes were used for summarizing the collected data. Video and audio recording, and a field diary also supplemented data collection.

Interviews' data analysis was based on content analysis (YIN, 2001). Content analysis was benefitted by the complementary vision of the researchers, from Design and Production Engineering fields. Emergent categories were also confronted with previous published works (LOVLIE et al., 2009; ERICSON, 2009; ROTTINGEN et al., 2009; SECOMANDI et al., 2009).

\subsection{Activities Description}

\section{Stage 0: Recognition and Acknowledgement}

This preliminary stage took six months. It comprehends the activities of understanding the potential of the proposed research by HMD, and, more importantly, of identification of possible field units and applications by the research team. Also comprises the formalization of the proposed project and the evaluation by the Hospital's Ethics and Research Committee.

ICU has 32 beds to assist severely ill patients and attends a monthly average of 114 people, being divided in three categories of treatment complexity (High, Medium and Low). 


\section{Stage 1: Diagnosis}

This stage lasted five months and consisted on the application of a series of tools that allowed the researchers to evaluate the point of view of the nursing technician regarding the object of study. In parallel, analyses of the client's value perception were conducted under the perspective of the assistant doctor, since this professional is responsible for referring the patients for the ICU. Based on this analysis, three possible focuses for the project were identified (Figure I).

Data collection was followed by a six-hour continuous immersive observation (shadowing) representing the complete workday of the ICU's nursing technicians. Video and audio recordings, and field notes about the researcher's perceptions during the data collection activity were used to collect data. The focus during the recording was to observe behaviors, structures involved in the activities, relationships and processes the nursing technician had contact with during the work shift. The focus was not properly to diagnose issues, but to observe the technician's difficulties and to produce insights of possible solutions for improving the observed activities.

Figure I - Synthesis of Stage 1 - Diagnosis

\section{Stage 1: Diagnosis}

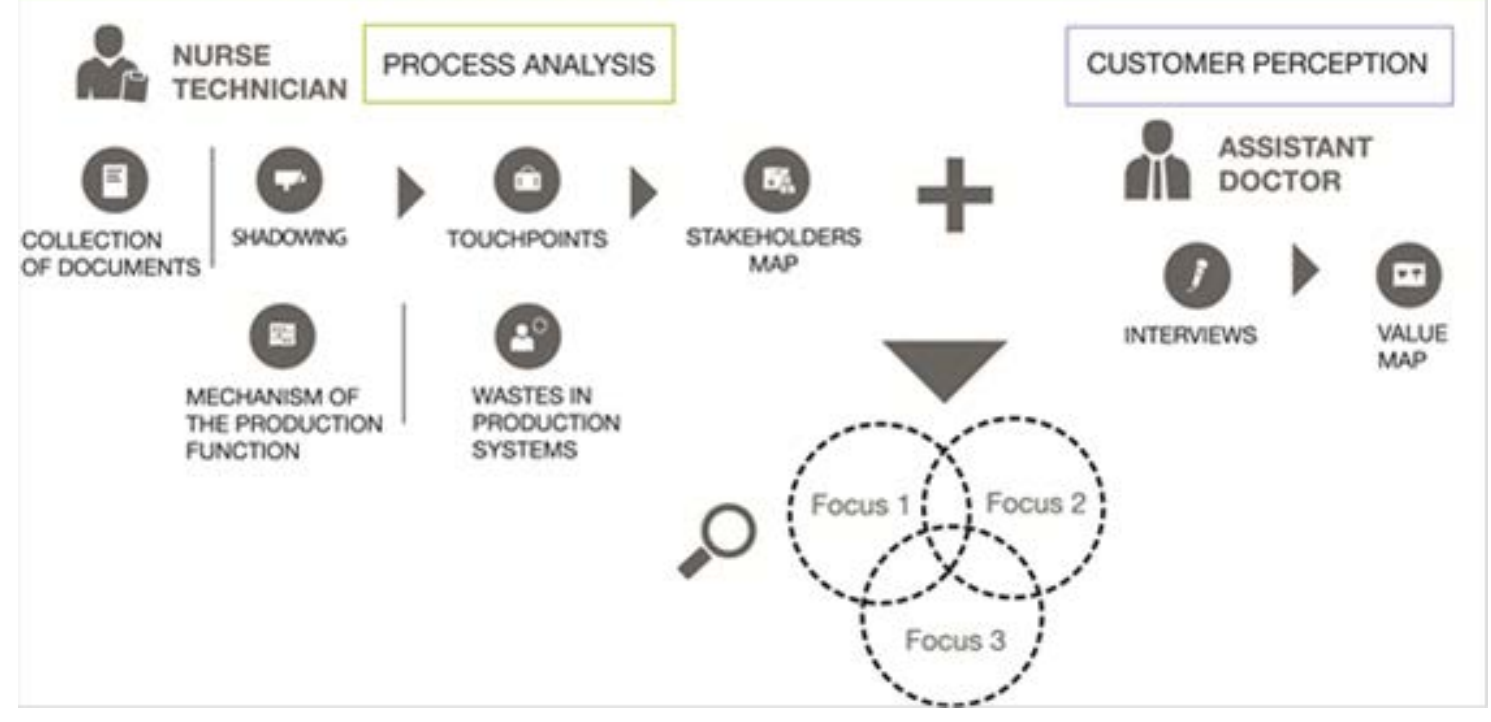

The processes and associated wastes were also observed, such as inadequately projected activity flows, reworks during the workday, unnecessary movements, among others. Interferences from and relations with other colleagues 
were also observed, as well as the influences of the environment, of the supplies, of the physical space, and of the interaction with other actors.

Under the perspective of evidences, the researchers collected the number of steps (with a step counter) and the distance the technicians made in each of the facilities of the ICU to perform their tasks throughout a workday. Data collection was performed daily during one month. Technicians caring of High Complexity patients roam an average of $3.98 \mathrm{~km}$, against $3.13 \mathrm{~km}$ and $4.08 \mathrm{~km}$ for those caring of Medium and Low Complexity patients, respectively. These data is influenced by the average number of beds each technician takes care for each type of complexity. They help to justify why the focus of the research was on the nursing technician. This observation allowed inferring that better-projected layouts could lead to maintain the nursing technician closer to the patients, where they really add value. The following causes were raised for the excess of movements: (i) the layout is not adequately projected, and the technicians had to move around to grab equipment, medicine and other supplies; (ii) technicians were moved away from the patient care by auxiliary activities, such as get medicine at the hospital's pharmacy, or separating documents, or other activities that make the technicians add less value than they could.

The percentage of value added by the technicians' work was mapped, based on the principles of the MPF (SHINGO, 1996), aiming at analyzing the technician (object of the flow) and the subjects that act in time and in space, highlighting improvement actions. The obtained results are presented in Table II. 
Table II - The results of the nursing technician's MPF at ICU-HMD

\begin{tabular}{|c|c|c|c|c|c|c|}
\hline Activity & $\begin{array}{l}\text { Number of } \\
\text { Operations }\end{array}$ & Transportation & Inspection & Waiting & Processing & $\begin{array}{l}\text { Non- } \\
\text { Value } \\
\text { Added }\end{array}$ \\
\hline Duty transition & 6 & $33.33 \%$ & $16.67 \%$ & $16.67 \%$ & $33.33 \%$ & $66.67 \%$ \\
\hline Box transition & 5 & $40.00 \%$ & $20.00 \%$ & - & $40.00 \%$ & $60.00 \%$ \\
\hline Patient's cleaning & 10 & $60.00 \%$ & - & - & $40.00 \%$ & $40.00 \%$ \\
\hline Medical prescription & 5 & $33.33 \%$ & $33.33 \%$ & $16.67 \%$ & $16.67 \%$ & $83.33 \%$ \\
\hline $\begin{array}{l}\text { Medication } \\
\text { maintenance }\end{array}$ & 15 & $40.00 \%$ & $6.67 \%$ & $6.67 \%$ & $46.67 \%$ & $53.33 \%$ \\
\hline Box tasks & 5 & $60.00 \%$ & - & - & $40.00 \%$ & $60.00 \%$ \\
\hline Vital signs monitoring & 5 & $40.00 \%$ & $20.00 \%$ & - & $40.00 \%$ & $60.00 \%$ \\
\hline Patient's diet & 7 & $28.57 \%$ & $28.50 \%$ & $14.29 \%$ & $28.57 \%$ & $71.43 \%$ \\
\hline Average & & $42.37 \%$ & $10.17 \%$ & $10.17 \%$ & $37.29 \%$ & $62.71 \%$ \\
\hline
\end{tabular}

From the observation of the processes involved in the activity of the nursing technician and the average results, it becomes clear the importance of reconsidering activity elements for a better efficiency. The high level of wastes due to transportation represents the reason why the technicians move around so much throughout the previously measured workday. This analysis does not mean eliminating all the nonvalue-added activities at once, but allows understanding the potential for improvements by rationalizing activities that prevent the technician of performing the patient's caring (value-added) activities.

On the other hand, observing the process from the point of view of the patient and his or her value perception also produces relevant information. This task was accomplished by using the Value/Expectations Map tool, considering, as actors: the relative/responsible for the patient; and the assistant doctor. Priority was given to the perception of the assistant doctor, due to the asymmetry of technical information and to the ICU's focus on improving processes for the patients under the point of view of nursing technicians.

The involved team focused the SD + MPF project on the duty transitions among technicians. Despite this process was judged as fundamental for most of the actors considered on the research, it was performed informally. Also, the following reasons were presented: (i) high potential impact on the operation with lower effort, according 
to Senge's (1998) principle of leverage; and (ii) duty transitions are a critical matter for the nursing area (SILVA and CAMPOS, 2007).

\section{Stage 2: Creating and Thinking}

The creating and thinking stage lasted three months, comprising the activities presented in Figure II. A new immersive activity was performed to deepen the understanding about the duty transition process. Also, the research team performed direct observations of the three shift turns, stratified by the high, medium and low complexity areas. At the same time, the researchers intensified their knowledge about the technicians' obligations and activities, by using internal ICU's documents. The involved team then, produced a synthesis of the possible control variables to be addressed.

Figure II - Synthesis of Stage 2 - Create and Rethink

\section{Stage 2 - Create and Rethink}

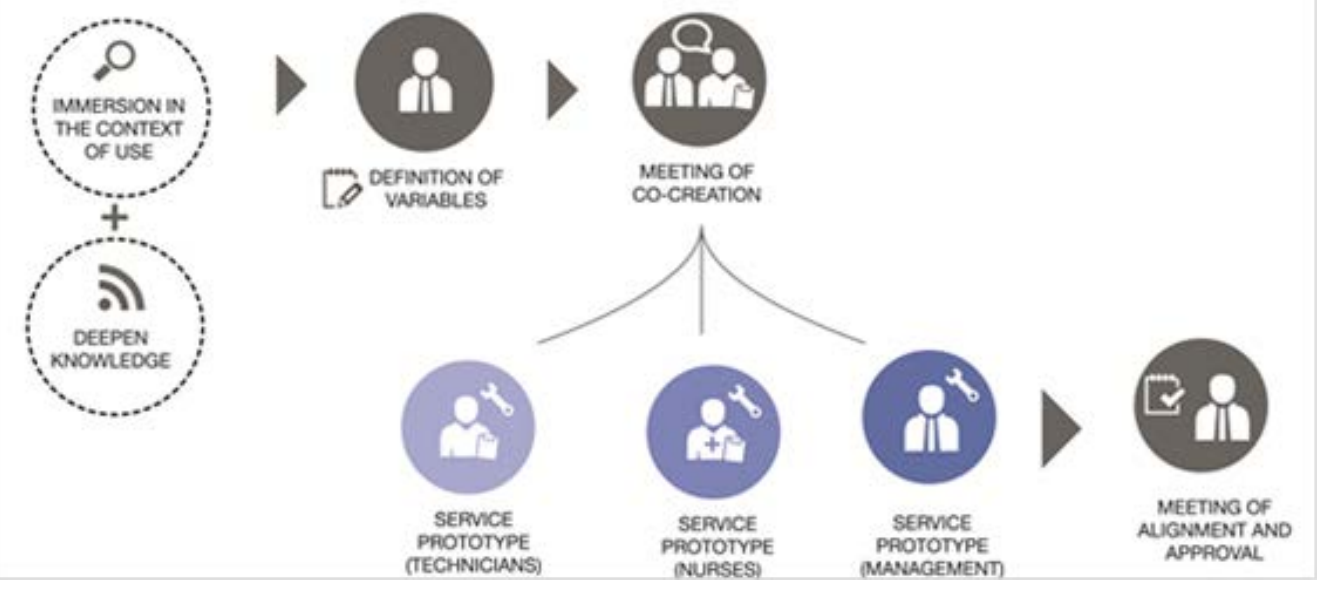

Co-creation meetings followed the control variables' definition activity. Three nursing technicians were selected by the ICU managers to discuss the technicians' duty transition with the research team. A cardboard and post-its were used to stimulate idea proposition and analysis. The technicians brought relevant elements about their activities: (i) synchronization: frequently, due to delays there is no direct interaction between the technician leaving the current shift and the technician on the next shift. The technician needs to leave their station, in order to respect the assigned working hours. In such cases, information is passed through other colleagues, indirectly; (ii) complicity: technicians tend to perform unfinished tasks from colleagues holding the 
station in previous shifts, leading to work-and-rework. This can also be caused by a permissive behavior about the work standardization of the shift transition protocol; (iii) relationship: the lack of complicity between nurses and technicians potentially generates non-value-added activities. Other subjects of discussion were the Vital Signs Sheet (a document in which the technicians monitor the care indicators during the entire work shift), and the Checklist of Activities and the causes of deviance of such protocol. The participants suggested also improvements on the already existing Vital Signs Sheet.

After the first co-creation meeting, the researchers summed up a checklist with the relevant items for the routine management of the technicians. The prototype was analyzed and refined with the technicians in a series of focused meetings. Throughout the meetings, rapid service prototypes were made focusing on better layout and information organization. Improvements on the Vital Signs Sheet were also made. The estimated achievements of the new versions were: (i) increased space to inform the patient's evolution; (ii) a specific space for the technician's description of events at each shift (morning, afternoon and night) on the same day; (iii) horizontal orientation of the page, for easier handling; (iv) increased space for exams, patient's belongings, visitors registration, and other information; (v) elimination of deprecated fields, according to the current protocol.

The benefits the team estimated from the Duty Transition Checklist developed were: (i) standardization of a fundamental process regarding the patient's safety; (ii) promotion of changes in the behavior and engagement of the technicians; (iii) standardization of a duty transition routine, based on documental remarks; and (iv) promotion of explicit definitions and formal training (for instance, standard organization procedures).

The refined prototypes were then presented to the ICU's management team for assessment, adjustment and approval. A total of 3 versions of the checklist were developed. Version 3 was officially sent to the Medical Registers Committee of HDM, for formal approval. The new Vital Signs Sheet was also appreciated by the ICU's management team, but its implementation was not recommended by the managers for the following reasons: (i) it contains patients' control data and its implementation affects all ICU's processes, which would be too complex for the project horizon; (ii) the current Vital Signs Sheet is a formal document archived by the hospital, for proving the 
administration of the treatment and external actors can also have access to the registered information; (iii) it would depend on a specific approval of the Medical Registers Committee. This shows the difficulty of implementing changes in the Healthcare context, especially when it straightly involves control and care of the patient's health.

\section{Stage 3: Implementation}

The implementation stage was carried out during 4 months. A synthesis of the steps followed in this stage can be observed in Figure III. For the first implementation test, the Medium Complexity area was selected as the first pilot. Three meetings, one per shift, were conducted with the teams of nursing technicians, aiming to explain the process changes in their routines, why the change was being made, and what would be the benefits for the different involved actors.

Figure III - Synthesis of Stage 3 - Implement

\section{Stage 3: Implement}

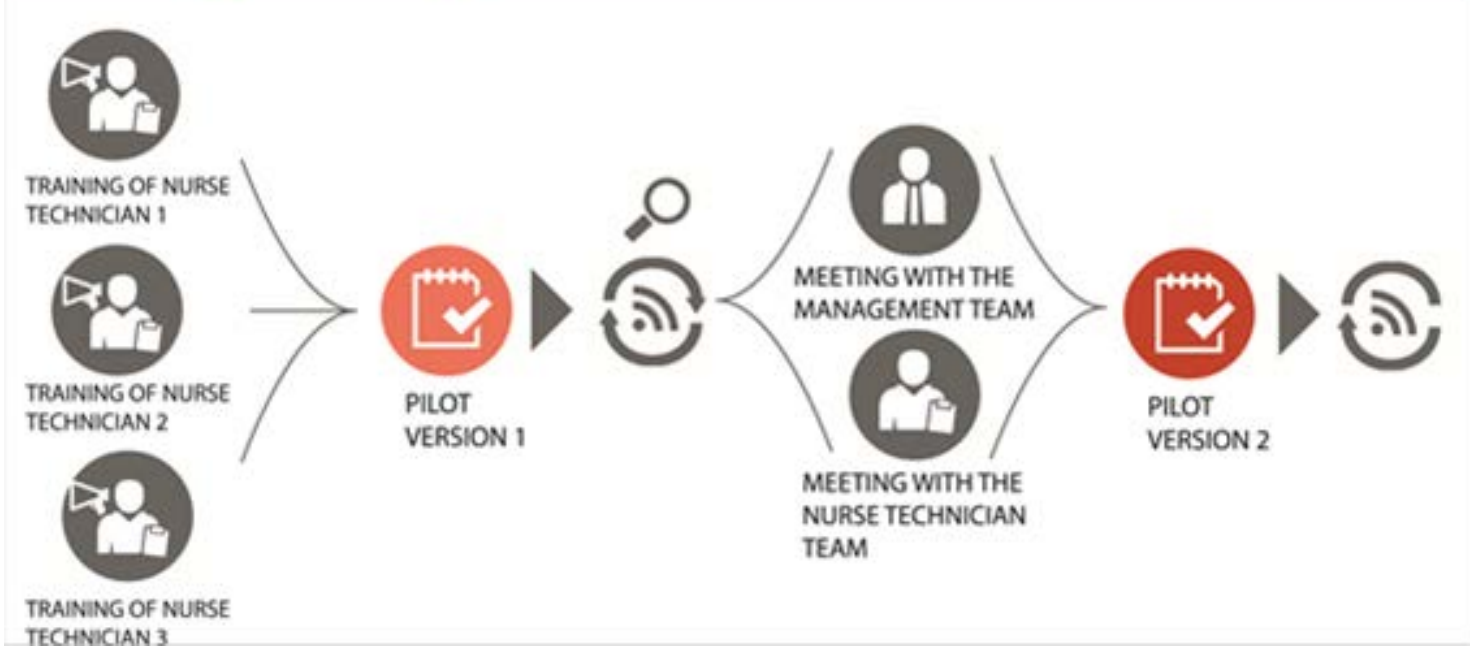

The research team accompanied the activities during three weeks, clarifying any doubts. After the third week, a meeting among the researchers and the nursing manager was conducted to evaluate the change process and the produced work. The participants observed that the order of the items in the checklist was not clear, creating doubts about which items had been properly reported or executed. A suggestion emerged of separating the items in a more visual way. 
Collaborators who did not take part on the training meetings showed considerable resistance in supporting the project and changing their routine. This fact, could result on undesired influence over other collaborators. One observed factor was the misunderstanding that the change was top-down (from the organization to the technician), and some technicians felt invaded, showing resistance. This subject was also treated at the meeting with the ICU managers and the team decided to complete a month of use with the pilot version of the document, while a refined version to be used from the following month was prepared. To develop the second version, the researchers interacted with all the technicians at their workplace, and presented the improvements on the sheet, so they could give their opinion about the new version.

When the new of the Duty Transition Checklist was presented (Figure IV), the technicians considered it well fitted, clearer and easier to understand and to fill up. It was also considered more ludic and intuitive by them. This new version was tried for another month at the Medium Complexity area before being implemented for the other two areas of the ICU.

Figure IV - Shift Change Checklist (version 5) for Nursing Technicians

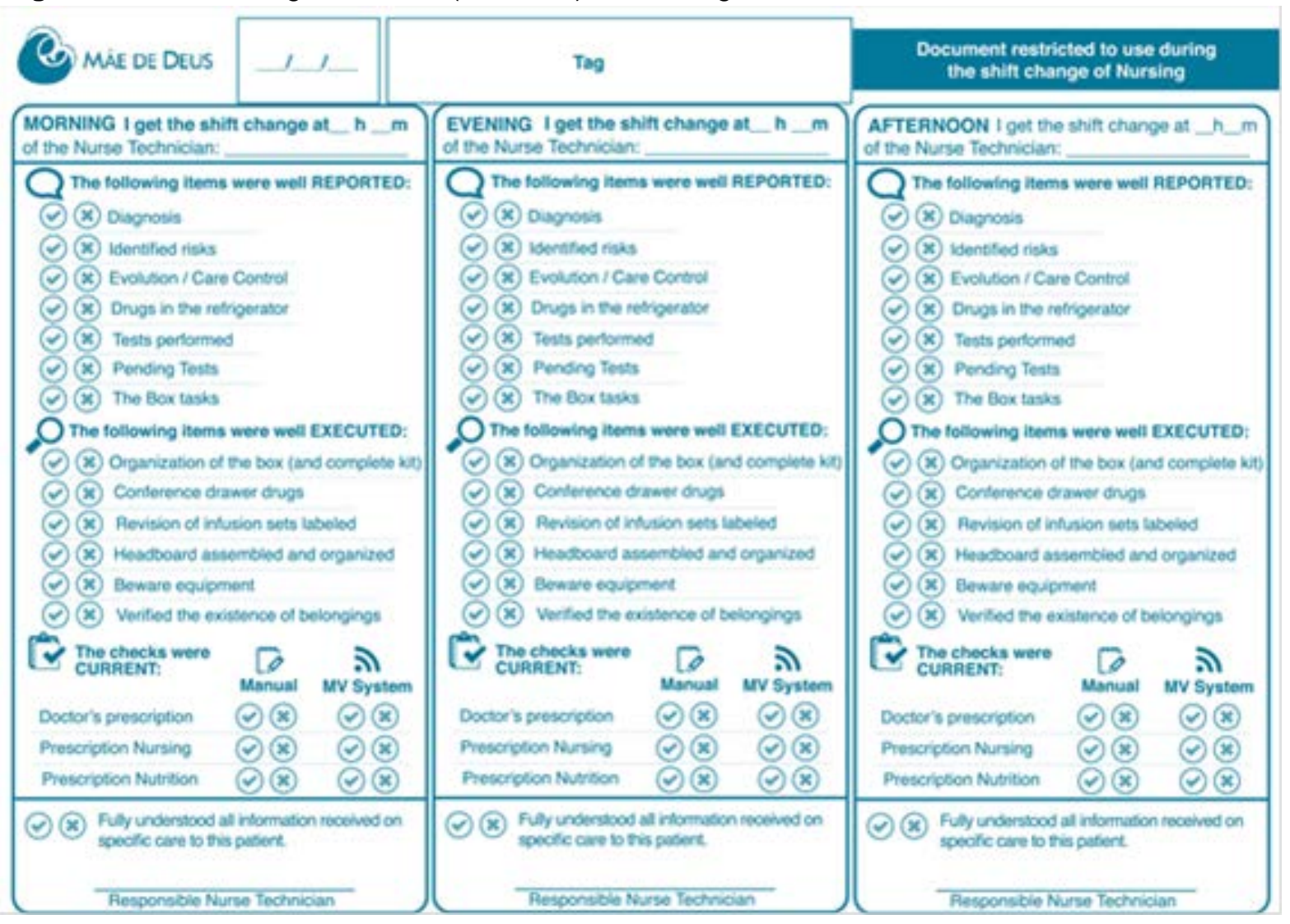


The items controlled at check-list are linked to important dimensions for the management and also to comply with the requirements of regulatory bodies as Federal Council of Medicine and Nursing, in addition to hospital certifications in which the organization has ( $\mathrm{JCl}$ and $\mathrm{ONA})$, as follows: 1) reports on the major routines of the patient and checks your medical condition (diagnosis; identified risks; evolution and care control; drugs in the refrigerator; tests performed and pending, as well as box tasks); 2) execution of significant management activities of each box work (organization of the box and complete kit; conference drawer drugs; review of infusions sets labeled; headboard assembled and organized; beware equipment; and verified the existence of belongings the patient or responsible); 3) patient information conference and the medical staff of manual and computerized form (medical prescriptions, nursing and nutrition).

\section{ANALYSIS AND DISCUSSION}

The global process of SD is open and cyclical and allows interventions throughout the process (MORITZ, 2005). During the conduction of this research, the main influences from the perspective of the evidences for the global process of SD aligned with the perspective of using MPF concepts, from OM/IE - were the constant concerns of: (i) conducting a replicable method for new studies; and (ii) searching for "scientific evidences" for sustain the actions taken throughout the project. SD, when based on experiences, has the goal of demonstrating a particular cultural reality as best as possible, considering the client's value perception as part of that context (CARR et al., 2011; BATE and ROBERT, 2006).

This complementary evidences perspective, which aims to find ways to categorize the collected data, for instance, on Value Map structures, thinking about future replications of this case for other Healthcare contexts, can produce a synergetic dynamic: designers can learn from consistent data collected previous cases before entering in a new cultural context; and each new application can produce new comparable data for refining the conception about the most suitable courses of action. Thus, this integrated view can lead to different ways of categorizing and organizing information from the hospital context, in the sense proposed by Freire and Sangiorgi (2010), as illustrates Figure V. 
This value maps structure contemplates an "affective structure" to support the actors. Differently from other corporative contexts, in Healthcare contexts the actors frequently deal with matters of insecurity, lack of control, embarrassment, struggle between life and death and, because of that, they demand more Psychology-related structures. The externalization of such perspective as proposed in the structure presented in Figure $\mathrm{V}$ allows focusing SD on such dimension, thus leading to a potentially more robust approach.

Figure $\mathbf{V}$ - Value map within the hospital

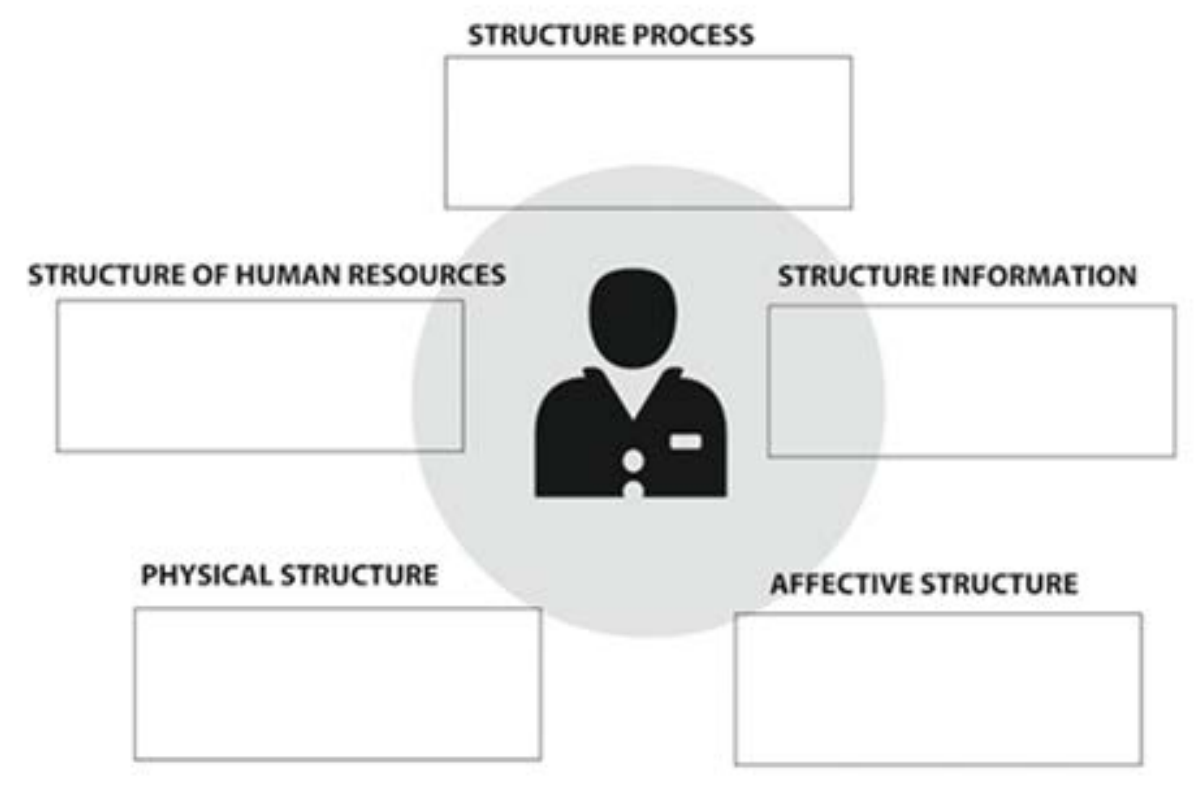

On the same sense, integrating SD with MPF concepts provided focus on evidence collection and supported the prioritization process of improvement proposals of the SD project. It also kept the focus on a process perspective present, hierarchizing tactical and operational actions. The MPF concepts provide a different perspective from the SD, not dividing the system into physical evidences, but into a network of processes and operations, independently analyzed to diagnose wastes or errors that determine the core of the problem. Considering the observed context, each contact point or identified process unleashes several internal factors that are essential to the patient's care. In this sense, many key operations can be diagnosed and re-projected in a more suitable way if considered as parts of an integrated process rather than independently - specially those related to the care of the patient and his or her safety. 
If SD provides a more horizontal and broad perspective, MPF contributes by bringing a vertical perspective of focusing on improvements that mitigate the root causes of problems. The analysis of the ICU technician's wastes during patients' care and the separation in processes and operations, more than in contact points, created a deeper and more measurable focus for the SD project (Figure $\mathrm{VI}$ ): the diagnosis becomes improving the management process of technicians' duty, not just the communication of the material support; the checklist was a way to standardize management and control the process.

Figure VI - The integrated SD+MPF approach



The study also allows understanding the impacts of cultural change can be, when implementing improvements on Healthcare. ExBD can support such analysis by providing tools considering empathy and engagement of the involved employees (BATE and ROBERT, 2006; CARR et al., 2011). According to Biehl (2007), it is necessary to consider the moment of the project in which the users' engagement occur, because, if it does not happen during the early stages, it can lead to the project's failure, for the people will develop resistance and it will become an obstacle. According to Somers and Nelson (2001), Murray and Coffin (2001) and Yang et al. (2006), insufficient training and engaging of all involved users can be an error that echoes negatively on the implementation. So, to integrate evidences and experiences in a project for a hospital sector, a project model should reserve a longer time for the diagnosis (in which there is a global approach based on experience and a justification 
of the focus based on evidences of the processes) and for the implementation (in which the focus must be on experiences for a cultural change and on the evidences for planning the change management and the results measurement). This proposal is illustrated in Figure VII.

Figure VII - Stages Project integrating evidence and experience in the context of hospital

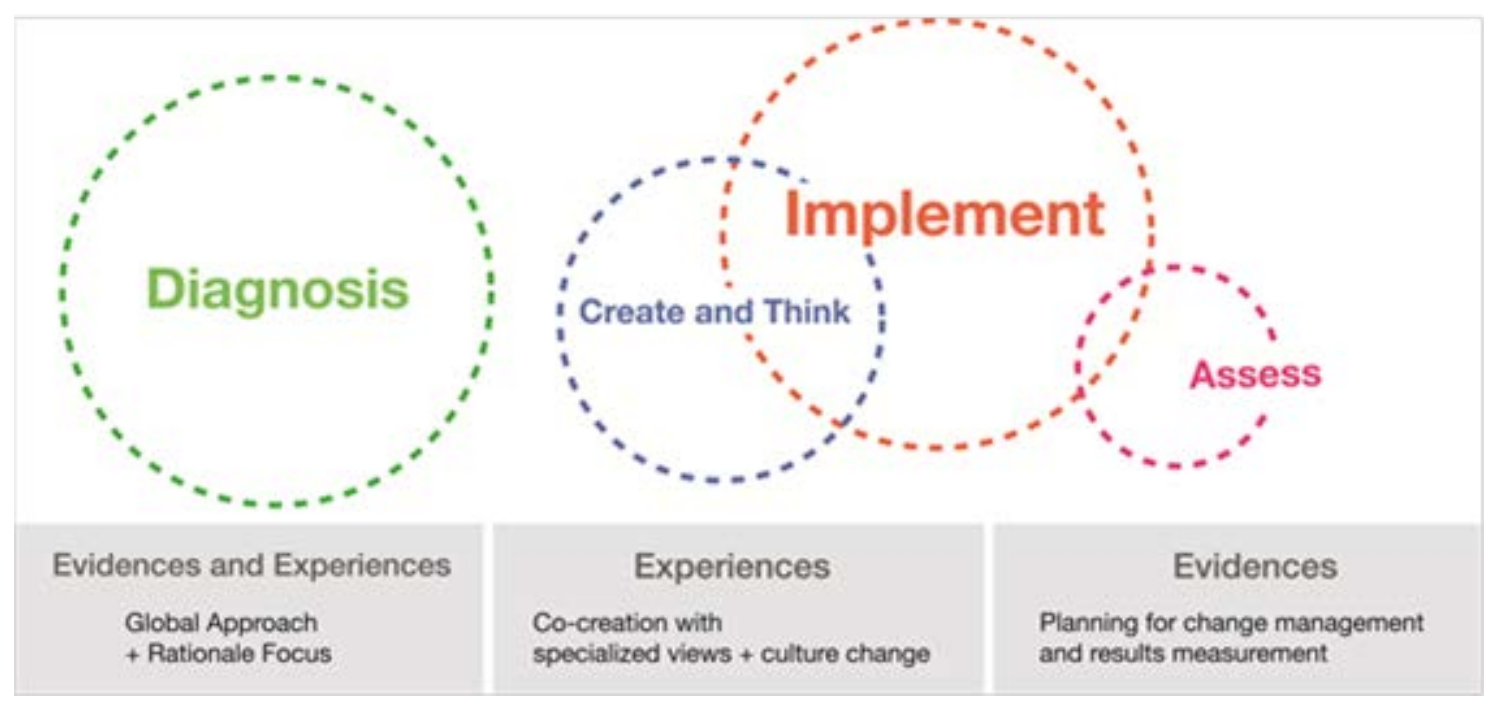

\section{FINAL REMARKS}

Developing a Design project involves answering the question "what to do?" (CELASCHI, 2007). What can lack of answers under the client's or manager's perspective is the question "why doing it?". MPF is based on quantifiable evidences and seeks for improving the added value of a process by eliminating unnecessary operations and processes. Integrating SD and MPF can produce a more robust way to justify and define focus of improvements. Therefore, it is possible to determine that a Design project will be made with, say, an " $X$ " focus, because it has a very high loss index, rework or waste is above the goal etc. This logic helps to justify the "why" After, when the "how to" has to be determined, come Design tools, creativity and so on.

Despite the potentially positive results obtained in the described application, limitations must be considered. The application in this specific context does not allow understanding the trade-offs and complexities associated to applications in other Healthcare contexts or operational units. Also, technicians' and other actors' participation cannot be considered as integral, due to unpredictable priority demands 
of their activities. Other actors could bring different or deepen evidences of the analyzed context, influencing the proposed approach described in this paper. In the researched context, patients were mostly found unconscious or with no condition of evaluating their experience with the hospital service. On a contrary situation, in which the patient found him or herself lucid and conscious, the Psychology sector of the hospital would be of great importance, because it would be possible to get information related to the patient's perceptions based on evidences and experiences, something that was not possible to evaluate with this research.

In the Healthcare context, being guided only by the patient has no use. It is necessary to involve other actors on the creation of the service. Healthcare is a specialized knowledge intensive area, making mandatory the direct involvement of collaborators, and the implementation and creation stages to happen almost simultaneously. At the same time, the study allowed to infer about the importance of planning the change process management, and of evaluating the changes during the implementation, so that the organization could converge towards the change. People will engage in what they helped creating and it can be either a bottleneck or a leverage point for a successful implementation.

The proposed SD+MPF conjoint approach can help finding evidences for changes on a hospital context demonstrated to be productive. Future work include replicating the research approach in other public and private hospitals, to compare contextual similarities, differences and their influence over the obtained results, as well as, creating a base of case evidences, for refining the proposed approach and its ability of promoting change.

\section{REFERENCES}

ANGROSINO, M. Etnografia e observação participante. Porto Alegre, RS: Artmed, 2009.

ANTUNES, J. A. V., ALVAREZ, R., PELlEgRIN, I., KLIPPEL, M. and BORTOLOTTO, P. Sistemas de produção: conceitos e práticas para projeto e gestão da produção enxuta. Porto Alegre, RS: Bookman, 2008.

ARREGUY-SENA, C., OLIVEIRA, R. M. L., LIMA, D. M. L., VASCONCELLOS, C. M. R. and SACRAMENTO, E. L. Construção e utilização de um painel informativo para passagem de plantão: relato de experiência. Revista Eletrônica de Enfermagem, v. 3, n.1, p. 27-44, 2001. http://dx.doi.org/10.5216/ree.v3i1.695. 
BATE, P. and ROBERT, G. Experience-based design: from redesigning the system around the patient to co-designing services with the patient. Quality and Safety in Health Care, v. 15, n. 5, p. 307-310, 2006. http://dx.doi.org/10.1136/qshc.2005.016527

BATE, P., ROBERT, G. and BEVAN, H. The next phase of healthcare improvement: what can we learn from social movements?. Quality and Safety in Health Care, v.13, n.1, p. 6266, 2004. http://dx.doi.org/10.1136/qshc.2003.006965

BIEHL, M. Success Factors for Implementing Global Information Systems. Communications of the ACM, v.50, n. 1, 2007. http://dx.doi.org/10.1145/1188913.1188917

BORBA, G. S. Princípios e variáveis da aprendizagem organizacional para a implantação de sistemas integrados de gestão em ambientes hospitalares. Tese (Doutorado) - Programa de Pós-Graduação em Engenharia de Produção da Universidade Federal do Rio Grande do Sul, Porto Alegre/RS, 2005.

BRANDT, R., CHONG, G. and MARTIN, W. Design informed: driving innovation with evidence-based design. Wiley, The American Institute of Architects, Canadá, 2010.

CARR, V., SANGIORGI, D., BUSCHER, M., JUNGINGER, S. and COOPER, R.Integrating Evidence-Based Design and Experience-Based Approaches in Healthcare Service Design. Heard Journal, v. 4, n. 4, p. 12-33, 2011. http://dx.doi.org/10.1177/193758671100400403

CELASCHI, F.Dentro al progetto: appunti di merceologia contemporânea. In: CELASCHI, F.; DESERTI, A. Design e Innovazione: strumenti e pratiche per la ricerca applicata. Carocci. Roma: Editore, 2007.

ERICSON, G. Great expectations: the healthcare journey. Touchpoint: The Journal of Service Design, v. 1, n. 2, p. 83-89, 2009.

FREIRE, K. and SANGIORGI, D. Service design \& healthcare innovation: from consumption to co- production and co-creation. Second Nordic Conference on Service Design and Service Innovation: ServDes, 2010.

GRAZIER, K. L. Collaboration and quality in managed care. Journal of Healthcare Management, v.44, n. 3, p. 163-166, 1999.

HMD - Hospital Mãe de Deus. Apresentação Institucional. 2012. available at: http://www.maede deus.com.br/2010/Institucional/Hospital-Mae-de-Deus.aspx. Aaccessed 12 December 2012.

LEE, S. Evaluating serviceability of healthcare servicescapes: service design perspective. International Journal of Design, v. 5, n. 2, 2011.

LIKER, J. O modelo Toyota: 14 princípios de gestão do maior fabricante do mundo. Porto Alegre, RS: Bookman, 2005.

LOCKWOOD, T. and WALTON, T. Building design strategy: using design to achieve key business objectives. Allworth Press, New York, NY, 2008.

LOVLIE, L., REASON, B., MUGGLESTONE, M. and ROTTINGEN, J. A healthy relationship. Touchpoint: The Journal of Service Design, v.1, n.2, p. 11-19, 2009. 
MORITZ, S. Service design, pratical acess to an envolving field. London, UK: KISD, 2005.

MURRAY, M.G. and COFFIN, G.W. A case study analysis of factors for success in erp system implementations. Seventh Americas Conference on Information Systems, 2001.

OHNO, T. O sistema Toyota de produção: além da produção em larga escala. Porto Alegre, RS: Bookman,1997.

ROTTINGEN, J. A healthy relationship. Touchpoint: The Journal of Service Design, v. 1, n.. 2, p. 11-19, 2009.

ROVATTI, K. Recordacões mnêmicas do paciente de terapia intensiva: qualidade de vida e prevalência de transtorno de estresse pós traumático. Dissertação (Mestrado).

UNISINOS. São Leopoldo, 2010.

SECOMANDI, F., HULTINK, E. and SNELDERS, D. From quality surveys to new touchpoints - a challenge for Service Design. Touchpoint: The Journal of Service Design, v. 1, n. 2, p. 43-45, 2010.

SENGE, P. M. A quinta disciplina. 2. ed. São Paulo, SP: Best Seller, 1998.

SHINGO, S.O Sistema Toyota de produção: do ponto de vista da engenharia de produção. Porto Alegre, RS: Bookman, 1996.

SILVA, O., SACRAMENTO, S. and MEIRELES, M. (2006). A engenharia de produção nas instituições hospitalares: elementos para a identificação de fontes de desperdícios. ENCONTRO NACIONAL DE ENGENHARIA DE PRODUÇÃO - ENEGEP, 25., 2006. Anais... Fortaleza, 2006.

SILVA, S. and CAMPOS, O. Passagem de plantão na enfermagem: revisão de literatura. Cogitare Enferm, v. 12, n. 4, p. 502-507, 2007. http://dx.doi.org/10.5380/ce.v12i4.10077

SOMERS, T. M.; NELSON, K. The Impact of Critical Success Factors Across the Stages of Enterprise Resource Planning Implementations. Proceedings of the 34th Hawaii International Conference on System Sciences, 2001. http://dx.doi.org/10.1109/HICSS.2001.927129

THIOLLENT, M. Pesquisa-ação nas organizações. São Paulo, SP: Atlas, 1997.

VAN DIJK, RAIJMAKERS, K. This is service design thinking. Bis Publishers, Amsterdam, 2010. http://dx.doi.org/10.1111/j.1369-7625.2009.00574.x

VAN STAA, A., JADELOO, S., LATOUR, J. and TRAPPENBURG, M.Exciting but exhausting: experiences with participatory research with chronically ill adolescents. Health

Expectations, v. 13, p. 95-107, 2009. http://dx.doi.org/10.1111/j.1369-7625.2009.00574.x

WYE, L., SHAW, A. and SHARP, D. Designing a NHS friendly complementary therapy service: A qualitative case study. BMC Health Services Research, v. 8, 2008.

http://dx.doi.org/10.1186/1472-6963-8-173

YANG, C., TING, P. and WEI, C.A Study of the Factors Impacting ERP System Performance from the Users' Perspectives. The Journal of American Academy of Business, v. 8, n. 2, 2006. 
YIN, R. K. Estudo de caso: planejamento e métodos. 2. ed. Porto Alegre, RS: Bookman, 2001.

ZIMRING, C. Evidence-based design could help quality of care: Literature reviews shows impact on outcomes, Hospital Peer Review, September, 2004.

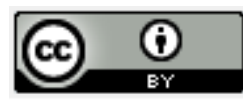

Artigo recebido em 31/10/2014 e aceito para publicação em 17/04/2015 DOI: http://dx.doi.org/ 10.14488/1676-1901.v15i2.1904 